\title{
natureoUTLOoK PROSTATE CANCER
}

17 December 2015 / Vol 528 / Issue No 7582

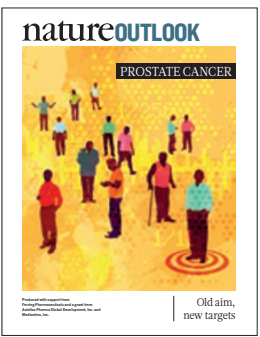

Cover art: Gary Neill

Editorial

Herb Brody

Michelle Grayson

Richard Hodson

Jenny Rooke

Art \& Design

Wesley Fernandes

Mohamed Ashour

Andrea Duffy

Production

Karl Smart

Ian Pope

Mira Loutfi

Sponsorship

Janice Stevenson

Samantha Morley

Marketing

Hannah Phipps

Project Manager

Anastasia Panoutsou

Art Director

Kelly Buckheit Krause

Publisher

Richard Hughes

Chief Magazine Editor

Rosie Mestel

Editor-in-Chief

Philip Campbell
$\mathrm{L}$ ive long enough, and most men will develop prostate cancer. Globally, it is the second most common cancer in men, and in some places it takes the top spot (page S118). As the prime reproductive years fade, the gland typically begins to misbehave. The first sign that men often experience is inflammation - a condition that is sometimes, but not always, a precursor to cancer. The interplay between inflammation and cancer remains an area of intense research (page S130).

Prostate-cancer screening has provoked contentious debate (page S120). Blood tests for prostate-specific antigen (PSA) have led to the discovery of cancers at earlier and more treatable stages. But they have also revealed many tumours that could safely be left untreated. Researchers are looking beyond PSA to other biomarkers that could be used to tell more reliably which cancers need treatment (page S124). Often, the best therapeutic option is just to be vigilant - 'active surveillance' is now the norm (page S126). When a trip to the operating theatre is unavoidable, robotics is making prostate surgery less likely to cause adverse effects (page S132).

Hopes for a vaccine have dimmed (page S134). The only approved immunotherapy for prostate cancer - sipuleucel-T - adds mere months to survival time and is expensive. Researchers are focusing on combinations of therapies, such as a checkpoint therapy administered together with a drug that targets tumour hypoxia. Because prostate tumours are most dangerous once they escape the gland itself, intense efforts are targeting metastatic cancers that have become resistant to standard treatments (page S128).

We are pleased to acknowledge support from Ferring Pharmaceuticals and a grant from Astellas Pharma Global Development, Inc. and Medivation, Inc. in producing this Outlook. As always, Nature retains sole responsibility for all editorial content.

Herb Brody

Supplements Editor
Nature Outlooks are sponsored supplements that aim to stimulate interest and debate around a subject of interest to the sponsor, while satisfying the editorial values of Nature and our readers' expectations. The boundaries of sponsor involvement are clearly delineated in the Nature Outlook Editorial guidelines available at go.nature.com/e4dwzw

CITING THE OUTLOOK

Cite as a supplement to Nature, for example, Nature Vol. XXX, No. XXXX Suppl., Sxx-Sxx (2015).

VISIT THE OUTLOOK ONLINE

The Nature Outlook Prostate Cancer supplement can be found at http://www.nature.com/nature/outlook/prostate-cancer

It features all newly commissioned content as well as a selection of

relevant previously published material.
All featured articles will be freely available for 6 months. SUBSCRIPTIONS AND CUSTOMER SERVICES For UK/Europe: Nature Publishing Group, Subscriptions, Brunel Road, Basingstoke, Hants, RG21 6XS, UK. Tel: +44 (0) 1256329242 Subscriptions and customer services for Americas - including Canada, Latin America and the Caribbean: Nature Publishing Group, 75 Varick St, 9th floor, New York, NY 10013-1917, USA Tel: +18663637860 (US/Canada) or +12127269223 (outside US/Canada). Japan/China/Korea: Nature Publishing Group Asia-Pacific, Chiyoda Building 5-6th Floor, 2-37 Ichigaya Tamachi, Shinjuku-ku, Tokyo, 162-0843, Japan. Tel: +81 332678751 CUSTOMER SERVICES

Feedback@nature.com

Copyright $\odot 2015$ Nature Publishing Group

\section{CONTENTS}

S118 PROSTATE CANCER

Small organ, big reach

An outline of the common cancer

S120SCREENING

Diagnostic dilemma

Reaching a consensus on screening

S123 PERSPECTIVE

Enforce the clinical guidelines

Monique Roobol discusses PSA testing

S124 PROGNOSIS

Proportionate response

Identifying the truly risky cancers

S126 TREATMENT

When less is more

The rise of active surveillance

S128 METASTASIS

Resistance fighters

Treatments for metastatic disease

S130 MICROBIOLOGY

Inflammatory evidence

The response could be a cancer cause

S132 Q\&A

A robot convert

Declan Murphy on robotic surgery

S134 THERAPY

An immune one-two punch

Combination therapy for prostate cancer

S137 PROSTATE CANCER

4 big questions

Key areas of research

RELATED ARTICLES

S138 Targeting the MLL complex in castration-resistant prostate cancer R. Malik et al.

S147 Is docetaxel the 'black widow' of mCRPC drugs?

B. C. Liaw \& W. K. Oh

S149 Comprehensive validation of published immunohistochemical prognostic biomarkers of prostate cancer-what has gone wrong? F. Huber et al.

S158 Optimizing prostate cancer survivorship care M. J. Resnick

S160 Who dies from prostate cancer? A. Patrikidou et al. 